\title{
Postural Control Dysfunction and Balance Rehabilitation in Older Adults with Mild Cognitive Impairment
}

\author{
Xuan Liu ${ }^{1,2,+}\left(\mathbb{D}\right.$, Michelle H. Chen ${ }^{2,3,+}$ and Guang H. Yue ${ }^{1,2, *}$ \\ 1 Center for Mobility and Rehabilitation Engineering Research, Kessler Foundation, \\ West Orange, NJ 07052, USA; XLiu@kesslerfoundation.org \\ 2 Department of Physical Medicine and Rehabilitation, New Jersey Medical School, Rutgers University, \\ Newark, NJ 07101, USA; MChen@kesslerfoundation.org \\ 3 Center for Neuropsychology and Neuroscience Research, Kessler Foundation, East Hanover, NJ 07936, USA \\ * Correspondence: GYue@kesslerfoundation.org; Tel.: +1-973-324-3539 \\ + These authors contributed equally to this work.
}

Received: 13 October 2020; Accepted: 18 November 2020; Published: 19 November 2020

check for updates

\begin{abstract}
Older adults with mild cognitive impairment (MCI) are at an increased risk for falls and fall-related injuries. It is unclear whether current balance rehabilitation techniques largely developed in cognitively intact populations would be successful in older adults with MCI. This mapping review examined the available balance rehabilitation research conducted in older adults with MCI. Databases Medline, Cinahl, Cochrane, PubMed, Scopus, and PsycINFO were systematically searched from inception to August 2020. Twenty-one studies with 16 original randomized controlled trials (RCTs) involving 1201 older adults with MCI (>age 60) met the inclusion criteria, of which 17 studies showed significant treatment effects on balance functions. However, only six studies demonstrated adequate quality (at least single-blind, no significant dropouts, and intervention and control groups are equivalent at baseline) and evidence (medium or large effect size on at least one balance outcome) in improving balance in this population, and none of them are double- or triple-blind. Therefore, more high-quality RCTs are needed to inform future balance rehabilitation program development for older adults with MCI. Moreover, few studies examined the incidence of falls after the intervention, which limits clinical utility. Future RCTs should prospectively monitor falls or changes in risk of falls after the intervention.
\end{abstract}

Keywords: mild cognitive impairment; postural control; falls; balance rehabilitation

\section{Introduction}

More than one in four adults aged 65 years and older fall each year [1,2]. Falls are the leading cause of fatal and non-fatal injuries among older adults [1,2]. In 2015, medical costs associated with older adult falls in the U.S. totaled USD 50 billion [3]. Cognitive impairment has been established as a significant risk factor for instability and falls among older adults [4]. Older adults with mild cognitive impairment (MCI) and dementia experience higher incidence of falls compared to cognitively intact older adults [5]. About $60 \%$ of older adults with MCI and dementia experience at least a fall every year, which is twice that of cognitively healthy older adults [6,7]. Cognitively impaired individuals are also more likely to experience injurious and non-accidental falls than their cognitively healthy peers $[8,9]$.

$\mathrm{MCI}$ is a condition characterized by modest cognitive decline that does not yet significantly compromise everyday life independence. It is a reversible, transition stage between normal aging and dementia [10], with a $14.9 \%$ conversion rate to dementia among older adults with MCI monitored for 
two years [11]. In dementia, there is significant cognitive decline such that the individual is unable to complete daily activities without assistance. According to the most recent American Academy of Neurology (AAN) practice guidelines [11], rates of MCI steadily increase with age, with $8.4 \%$ in adults between the ages of 65 and 69 years to $25.2 \%$ of adults between the ages of 80 and 84 years. Although MCI was first conceptualized as a prodromal stage for Alzheimer's disease, the current nomenclature refers to cognitive decline secondary to a variety of possible etiologies, including other dementing conditions (e.g., vascular dementia) as well as other neurologic and psychiatric disorders. MCI can be further categorized into amnestic (aMCI) and non-amnestic (nMCI) subtypes. aMCI is defined by predominantly memory dysfunction and more likely to represent a precursor to Alzheimer's disease. nMCI refers to decline in primarily non-memory domains and can be the result of a myriad of conditions.

Increased fall risk among older adults with $\mathrm{MCI}$ and dementia is presumed to be the result of neurocognitive changes [12]. Specifically, decline in attention, mental processing speed, visuospatial abilities, and executive functions (i.e., higher-order cognitive abilities such as cognitive flexibility, planning, and behavioral inhibition) are associated with a higher risk of future falls, even after adjusting for other risk factors such as demographic variables and prior fall history $[13,14]$. Unsurprisingly, older adults with nMCI show a significantly higher fall risk compared to older adults with aMCI, which can be attributed to impaired executive functioning [8]. Declining cognition has been associated with more "risky" mobility activities (e.g., not holding onto a grab bar for support when stepping into the bathtub) and increased fall rate [15]. Thus, increased fall incidence in older adults with MCI may be partially attributed to judgment errors.

The interplay between cognition and mobility has been extensively studied using cognitive-motor dual-task paradigms (i.e., performing cognitive and motor tasks concurrently). Cognitive-motor dual-task paradigms have allowed researchers to investigate more subtle changes in gait and postural control related to cognitive decline among healthy older adults and older adults with MCI [16,17]. Patients with cognitive impairment often exhibit an increased "dual-task cost", or a disproportionate decrement in performance under dual-task conditions compared to single-task conditions. Difficulties with dual-tasking are thought to reflect limited information processing capacity, and resource competition leads to performance decrement on one or both tasks [18]. The extent of dual-task difficulties depends on the severity of cognitive impairment, and older adults with MCI show a larger dual-task cost compared to healthy older adults [16,17]. Dual-tasking is an aspect of executive functions, which is often impaired in older adults with MCI. Importantly, poor dual-task performance, which is linked with conversion to dementia among older adults with MCI [19], is a significant predictor of future falls $[5,13]$.

Postural instability is a major risk factor for falls [20,21]. Postural control worsens as a function of the degree of cognitive impairment, with older adults with MCI exhibiting an intermediate capability of postural control, between healthy older adults and individuals with dementia [20,22-25]. Larger postural sway while standing has been observed among older adults with MCI relative to healthy controls [22,23,26,27]. A recent meta-analysis revealed that anterior-posterior and mediolateral sway while standing during eyes open (but not eyes closed) best discriminates between older adults with MCI and healthy controls [28]. The authors hypothesized that impairment in visual processing among older adults with MCI may underlie this observed difference and recommended the use of visual feedback in balance rehabilitation.

The neural correlates of falls and postural control are not well understood. Extant literature indicates that a history of falls is associated with reduced gray and white matter volume, white matter lesions, and altered functional connectivity in both healthy older adults and older adults with MCI [29-35]. Brain regions involved in executive, visual, and motor functions (e.g., prefrontal cortex, pre- and post-central gyrus, occipital lobe) are particularly affected [29,32,34]. A decreased ability to deactivate brain connectivity during a task (i.e., increased functional connectivity in the default mode 
network, which is normally activated at rest but deactivated during a task) has also been observed in elderly fallers with and without MCI [31,33].

It is unclear whether balance rehabilitation techniques used in populations with predominantly motor difficulties would apply to individuals with cognitive impairment. Cognitive impairment may interfere with the ability to benefit from training or generalize training to activities of daily living. The MCI stage may be an ideal time to intervene, as it is a transition stage between normal aging and dementia. Once the older adult meets the criteria for dementia, there may be fewer options available for intervention given the extent of neurodegeneration and reduced ability to learn from training. Therefore, the current review will examine the available balance rehabilitation research conducted in older adults with MCI, which will inform future research and clinical care (e.g., incorporating balance training into standard of care for older adults with $\mathrm{MCI}$ ).

\section{Materials and Methods}

A mapping review approach was selected to give an overview of the published randomized controlled trials (RCTs) which reported rehabilitation intervention effects on balance function in MCI. The purpose of this review was to identify gaps in the balance rehabilitation research for MCI and inform more specific future reviews and/or research studies on this particular area. The following databases were systematically searched from inception to August 2020: Medline (via EBSCOhost), Cinahl (via EBSCOhost), Cochrane, PubMed, Scopus, and PsycINFO (via Ovid). Searches used the following combination of keywords: (mild cognitive impairment) AND (exercise OR cognitive training) AND (balance OR postural OR fall).

Risk of bias was evaluated based on treatment allocation blinding (participants, assessors, and trainers), equivalency in baseline characteristics among treatment groups (or if differences were adequately accounted for in the analyses), and dropout rates [36]. Studies with significant dropout rates ( $>20 \%$ ) [36] were noted in Table 1. Effect sizes (Hedges' g) were calculated to determine the strength of the findings. For the effect sizes, pooled standard deviations from the experimental and control groups were weighted by sample sizes, and the baseline pooled standard deviations were used to calculate post-intervention effect size to minimize the influence of the interventions on the standard deviations [37]. Effect size was first calculated as the difference between the intervention and control groups at each time point (pre- and post-intervention). The difference between the two effect sizes were then derived as the final effect size for each comparison. Small sample sizes (total sample size $[\mathrm{n}]<50$ ) were corrected by multiplying the effect size with a bias correction factor $([n-3] /[n-2.25] \times \sqrt{[n-2] / n})$ [38]. Effect sizes were only calculated for studies purporting statistically significant group effects. 
Table 1. Sample characteristics, diagnosis, study design, and intervention paradigms in the RCTs included. Abbreviations: MCI mild cognitive impairment; MoCA Montreal cognitive assessment; DSM-IV diagnostic and statistical manual of mental disorders, fourth edition; CDR clinical dementia rating; MMSE mini-mental state examination; WMS-R Wechsler memory scale-revised; ICD-9-CM international classification of diseases, ninth revision, clinical modification; ACE Addenbrooke's cognitive examination; ADL activities of daily living.

\begin{tabular}{|c|c|c|c|c|c|}
\hline Author, Year & Sample Characteristics & $\begin{array}{l}\text { Primary Diagnosis Criteria for } \\
\text { MCI }\end{array}$ & Study Design & Training Intervention & Comparator Group (s) \\
\hline Anderson-Hanley et al., 2018 [39] & $\begin{array}{l}14 \mathrm{MCI} \text { adherent at } 6 \text { month, } \\
\text { enrollees ( } 83 \mathrm{MCI} \text { and } \\
28 \text { cognitively intact), age }>65, \\
\text { predominantly female }(66 \%)\end{array}$ & $\mathrm{MoCA}<26$ & $\begin{array}{l}3 \text { groups: exer-tour (low cognitive demand), } \\
\text { exer-score (high cognitive demand), and game-only } \\
\text { (no physical exercise, not examined at } 6 \text { month); } \\
\text { no blinding specified; } 83 \% \text { dropout rate; game-only } \\
\text { group reported more sedentary lifestyle (due to high } \\
\text { dropout rate for this non-exercising arm, researchers } \\
\text { recruited specifically individuals who elected for } \\
\text { this group) }\end{array}$ & $\begin{array}{l}\text { exer-tour: virtual reality bike rides, } \\
\text { exer-score: pedaling through } \\
\text { a videogame }\end{array}$ & $\begin{array}{l}\text { the same videogame operated by a } \\
\text { joystick or keyboard }\end{array}$ \\
\hline Choi and Lee, 2018 [40] & $\begin{array}{l}\mathrm{MCI}(\mathrm{n}=60) \text {, age }>65 \\
\text { predominantly female }(80 \%)\end{array}$ & $\mathrm{MoCA}<26$ & $\begin{array}{l}2 \text { groups: ground kayak paddling and control; single } \\
\text { (assessor)-blind }\end{array}$ & $\begin{array}{l}\text { paddling exercise performed while } \\
\text { sitting on chairs with and without a } \\
\text { balance foam }\end{array}$ & a home exercise program \\
\hline Choi and Lee, 2019 [41] & $\begin{array}{l}\mathrm{MCI}(\mathrm{n}=60) \text {, age } \geq 65, \\
\text { predominantly female }(85 \%)\end{array}$ & $\mathrm{MoCA}<26$ & $\begin{array}{l}2 \text { groups: virtual kayak paddling and control; single } \\
\text { (assessor)-blind }\end{array}$ & $\begin{array}{c}\text { paddling exercise in a } \\
\text { virtual environment }\end{array}$ & a home exercise program \\
\hline Donnezan et al., 2018 [42] & $\operatorname{MCI}(n=69)$, age $>65$ & $\begin{array}{l}\text { diagnosed by a neuropsychologist } \\
\text { with evidence of executive deficits }\end{array}$ & $\begin{array}{l}4 \text { groups: simultaneous cognitive and physical } \\
\text { training (PCT), physical training only (PT), cognitive } \\
\text { training only (CT) or a no-intervention control group; } \\
\text { no blinding specified }\end{array}$ & $\begin{array}{l}\text { simultaneous cognitive and } \\
\text { physical training: cognitive } \\
\text { training and physical training } \\
\text { delivered simultaneously within } \\
\text { the same intervention }\end{array}$ & $\begin{array}{l}\text { physical training: aerobic training } \\
\text { on bikes, cognitive training: } \\
\text { cognitive games, control: } \\
\text { no intervention }\end{array}$ \\
\hline de Oliveira Silva et al., 2019 [43] & $\begin{array}{l}19 \mathrm{MCI} \& 27 \text { Alzheimer's disease, } \\
\text { age } \geq 65\end{array}$ & $\begin{array}{l}\text { structured clinical interview to } \\
\text { assess mental disorders according } \\
\text { to the DSM-IV }\end{array}$ & $\begin{array}{l}2 \text { groups: exercise group, control group; single } \\
\text { (assessor)-blind; } 29 \% \text { dropout rate in intervention } \\
\text { group ( } 7 \% \text { in control group) }\end{array}$ & $\begin{array}{l}\text { multimodal physical exercise } \\
\text { (aerobic, strength, balance, } \\
\text { and flexibility) }\end{array}$ & $\begin{array}{l}\text { clinical follow-up without } \\
\text { physical training }\end{array}$ \\
\hline Mirelman et al., 2016 [44] & $\begin{array}{l}43 \text { fallers with MCI, } 109 \text { older } \\
\text { fallers, and } 130 \text { fallers with } \\
\text { Parkinson's disease, age } 60-90 \\
\text { sex stratified }\end{array}$ & score of 0.5 on the CDR scale & $\begin{array}{l}2 \text { groups: treadmill training plus virtual reality } \\
\text { interventions, treadmill training only; single } \\
\text { (assessor)-blind }\end{array}$ & $\begin{array}{l}\text { subjects watched their feet } \\
\text { projected on a screen via walking } \\
\text { on a treadmill with real-life } \\
\text { challenges (including obstacles, } \\
\text { multiple pathways, } \\
\text { and distractors) simulated }\end{array}$ & treadmill training alone \\
\hline Del Din et al., $2020[45]$ & $\begin{array}{l}38 \text { fallers with MCI, } 109 \text { older } \\
\text { fallers, and } 128 \text { fallers with } \\
\text { Parkinson's disease, age 60-90 } \\
\text { (subset from } \\
\text { Mirelman et al., } 2016 \text { [44] }\end{array}$ & score of 0.5 on the CDR scale & $\begin{array}{l}2 \text { groups: treadmill training plus virtual reality } \\
\text { interventions, treadmill training only; single } \\
\text { (assessor)-blind }\end{array}$ & $\begin{array}{l}\text { subjects watched their feet } \\
\text { projected on a screen via walking } \\
\text { on a treadmill with real-life } \\
\text { challenges (including obstacles, } \\
\text { multiple pathways, } \\
\text { and distractors) simulated }\end{array}$ & treadmill training alone \\
\hline Delbroek et al., 2017 [46] & 17 institutionalized MCI, age $\geq 75$ & $\mathrm{MoCA}<26$ & $\begin{array}{l}2 \text { groups: intervention (i.e., virtual reality dual-task } \\
\text { training using the BioRescue) or control group } \\
\text { (no additional training); single (assessor)-blind }\end{array}$ & $\begin{array}{l}\text { nine exercises which were used to } \\
\text { train balance, weight bearing, } \\
\text { memory, attention, } \\
\text { and dual tasking }\end{array}$ & no intervention \\
\hline Makizako et al., 2012 [47] & 47 aMCI, age $\geq 65$, female $46 \%$ & $\begin{array}{l}\text { intact general cognitive function, } \\
\text { MMSE 24-30, and having memory } \\
\text { impairment (assessed via } \\
\text { education-adjusted scores on the } \\
\text { WMS-R Logical Memory II) }\end{array}$ & $\begin{array}{l}2 \text { groups: multicomponent exercise or control group; } \\
\text { single (assessor)-blind }\end{array}$ & $\begin{array}{l}\text { combinations of aerobic exercise, } \\
\text { endurance walking, muscle } \\
\text { strength training, postural balance } \\
\text { retraining, and gait training }\end{array}$ & $\begin{array}{l}\text { attended two education classes } \\
\text { about health promotion }\end{array}$ \\
\hline
\end{tabular}


Table 1. Cont.

\begin{tabular}{|c|c|c|c|c|c|}
\hline Author, Year & Sample Characteristics & $\begin{array}{l}\text { Primary Diagnosis Criteria for } \\
\text { MCI }\end{array}$ & Study Design & Training Intervention & Comparator Group (s) \\
\hline Doi et al., 2013 [48] & $\begin{array}{l}47 \text { aMCI, age } \geq 65, \text { female } 46 \% \\
\text { (same cohort as in } \\
\text { Makizako et al., } 2012 \text { [47]) }\end{array}$ & $\begin{array}{l}\text { intact general cognitive function, } \\
\text { MMSE 24-30, and having memory } \\
\text { impairment (assessed via } \\
\text { education-adjusted scores on the } \\
\text { WMS-R Logical Memory II) } \\
\end{array}$ & $\begin{array}{l}2 \text { groups: multicomponent exercise or control group; } \\
\text { single (assessor)-blind }\end{array}$ & $\begin{array}{l}\text { combinations of aerobic exercise, } \\
\text { endurance walking, muscle } \\
\text { strength training, postural balance } \\
\text { retraining, and gait training }\end{array}$ & $\begin{array}{l}\text { attended two education classes } \\
\text { about health promotion }\end{array}$ \\
\hline Fogarty et al., 2016 [49] & 41 aMCI, age $>60$ & $\begin{array}{l}\text { based on an interview with the } \\
\text { participant and an informant about } \\
\text { history of cognitive concerns and } \\
\text { functional decline, and a review of } \\
\text { all available medical, } \\
\text { neurological, psychiatric, } \\
\text { and neuropsychological test data }\end{array}$ & $\begin{array}{l}2 \text { groups: a combined Taoist Tai Chi and memory } \\
\text { intervention group or memory intervention group; } \\
\text { no blinding specified; dropout rates were }<20 \% \text { but } \\
\text { those who dropped out had lower cognitive scores } \\
\text { than those who completed the interventions }\end{array}$ & $\begin{array}{c}\text { memory intervention plus a } \\
\text { low-impact exercise program } \\
\text { involving learning the practice of } \\
\text { Taoist Tai Chi }\end{array}$ & $\begin{array}{l}\text { a memory intervention program } \\
\text { for MCI }\end{array}$ \\
\hline $\begin{array}{l}\text { Hagovska and Olekszyova, } \\
2016[50]\end{array}$ & $78 \mathrm{MCI}$, age 65-75 & $\begin{array}{l}\text { confirmed by their psychiatrist and } \\
\text { psychologist and based on a } \\
\text { standard clinical examination and } \\
\text { neuropsychological testing, in line } \\
\text { with the criteria defined in the } \\
\text { ICD-9-CM } 331.83\end{array}$ & $\begin{array}{l}2 \text { groups: CogniPlus or control group, } \\
\text { no blinding specified }\end{array}$ & $\begin{array}{l}\text { selected exercises from the } \\
\text { CogniPlus program with } \\
\text { balance training }\end{array}$ & daily balance training \\
\hline Hagovska et al., 2016 [51] & $\begin{array}{l}78 \text { MCI, age 65-75 (same cohort as } \\
\text { in Hagovska and Olekszyova, } \\
2016 \text { [50]) }\end{array}$ & $\begin{array}{l}\text { confirmed by their psychiatrist and } \\
\text { psychologist and based on a } \\
\text { standard clinical examination and } \\
\text { neuropsychological testing, in line } \\
\text { with the criteria defined in the } \\
\text { ICD-9-CM } 331.83\end{array}$ & $\begin{array}{l}2 \text { groups: CogniPlus or control group, } \\
\text { no blinding specified }\end{array}$ & $\begin{array}{l}\text { selected exercises from the } \\
\text { CogniPlus program with } \\
\text { balance training }\end{array}$ & daily balance training \\
\hline Lam et al., 2011 [52] & $\begin{array}{l}329 \mathrm{MCI} \text {, age }>65 \text { (interim report } \\
\text { for RCT described in } \\
\text { Lam et al., 2012 [53]) }\end{array}$ & $\begin{array}{l}\text { CDR } 0.5 \text { or satisfying Mayo clinic } \\
\text { criteria for aMCI }\end{array}$ & $\begin{array}{l}2 \text { groups: mind body or control group; double } \\
\text { (assessor and trainer)-blind }\end{array}$ & 24-style Tai Chi & $\begin{array}{l}\text { muscle stretching and } \\
\text { toning exercises }\end{array}$ \\
\hline Lam et al., 2012 [53] & $261 \mathrm{MCI}$, age > 65 & $\begin{array}{l}\text { CDR } 0.5 \text { or satisfying Mayo clinic } \\
\text { criteria for aMCI }\end{array}$ & $\begin{array}{l}2 \text { groups: mind body or control group; double } \\
\text { (assessor and trainer)-blind; significant dropout rates } \\
\text { (46\% in experimental and } 22 \% \text { in control) }\end{array}$ & 24-style Tai Chi & $\begin{array}{l}\text { muscle stretching and } \\
\text { toning exercises }\end{array}$ \\
\hline Langoni et al., 2019 [54] & 52 sedentary MCI, age $\geq 60$ & $\begin{array}{l}\text { medical records, home visits, } \\
\text { and ACE score }\end{array}$ & $\begin{array}{l}2 \text { groups: strength and aerobic exercises group or } \\
\text { control group; single (statistician)-blind }\end{array}$ & $\begin{array}{l}\text { strength: ankle weights, elastic } \\
\text { bands, and dumbbells; } \\
\text { aerobic: walking }\end{array}$ & no intervention \\
\hline Langoni et al., 2019 [55] & $\begin{array}{l}52 \text { sedentary MCI, age } \geq 60 \\
\text { (same cohort as in } \\
\text { Langoni et al., } 2019[54] \text { ) }\end{array}$ & $\begin{array}{l}\text { medical records, home visits, } \\
\text { and ACE score }\end{array}$ & $\begin{array}{l}2 \text { groups: strength and aerobic exercises group or } \\
\text { control group; single (statistician)-blind }\end{array}$ & $\begin{array}{l}\text { strength: ankle weights, elastic } \\
\text { bands, and dumbbells; } \\
\text { aerobic: walking }\end{array}$ & no intervention \\
\hline Lipardo and Tsang, 2020 [56] & $92 \mathrm{MCI}$, age $\geq 60$, female $79 \%$ & $\begin{array}{l}\text { determined by a trained } \\
\text { neurologist-psychiatrist based on } \\
3 \text { criteria: cognitive level is not } \\
\text { normal nor demented, decrease in } \\
\text { cognitive ability, and normal } \\
\text { performance of basic ADL but with } \\
\text { slight impairment in } \\
\text { instrumental ADL }\end{array}$ & $\begin{array}{l}4 \text { groups: combined physical and cognitive training, } \\
\text { physical training, cognitive training, or waitlist } \\
\text { control group; single (assessor)-blind }\end{array}$ & $\begin{array}{l}\text { combined group: cognitive training } \\
\text { elements incorporated in each type } \\
\text { of exercise included in physical } \\
\text { training group; physical training: } \\
\text { multicomponent exercise program } \\
\text { on balance, strength, endurance, } \\
\text { and flexibility; cognitive training: } \\
\text { paper-based cognitive exercises on } \\
\text { executive function, memory, } \\
\text { attention, and orientation training }\end{array}$ & no intervention \\
\hline
\end{tabular}


Table 1. Cont.

\begin{tabular}{|c|c|c|c|c|c|}
\hline Author, Year & Sample Characteristics & $\begin{array}{c}\text { Primary Diagnosis Criteria for } \\
\text { MCI }\end{array}$ & Study Design & Training Intervention & Comparator Group (s) \\
\hline Lü et al., 2016 [57] & $45 \mathrm{MCI}$, age $\geq 65$ & $\mathrm{MoCA}<26, \mathrm{MMSE} \geq 24$ & $\begin{array}{l}2 \text { groups: a dumbbell-training group (DTG) or a } \\
\text { control group (CG); single (assessor)-blind }\end{array}$ & $\begin{array}{l}\text { dumbbell-spinning exercises } \\
\text { performed on the front part or } \\
\text { lateral side of the body }\end{array}$ & no intervention \\
\hline Sungkarat et al., 2017 [58] & $\begin{array}{l}59 \text { aMCI, age } \geq 60, \text { predominantly } \\
\text { female }(86 \%)\end{array}$ & $\begin{array}{c}\text { Petersen's criteria, MoCA }<26, \\
\text { MMSE } \geq 24\end{array}$ & 2 groups: Tai Chi or control; single (accessor)-blind & $\begin{array}{l}3 \text { weeks Tai Chi classes and } \\
12 \text { weeks practice at home }\end{array}$ & received educational material \\
\hline Yoon et al., 2017 [59] & 30 women with MCI, age $>65$ & Korean version of $\mathrm{MoCA}<23$ & $\begin{array}{l}\text { 3 groups: an elastic band-base high-speed power } \\
\text { training (HSPT), a low-speed strength training (LSST), } \\
\text { or a control group; no blinding specified; significant } \\
\text { dropout rates ( } 30 \% \text { in HSPT, } 53 \% \text { in LSST, and } 63 \% \text { in } \\
\text { control); did not report whether baseline } \\
\text { characteristics were equivalent among groups }\end{array}$ & $\begin{array}{l}\text { both exercise regimens were based } \\
\text { on the use of elastic exercise bands } \\
\text { (the elastic band-base HSPT } \\
\text { included a contraction phase } \\
\text { instructed to be carried out as } \\
\text { quickly as possible) }\end{array}$ & balance and tone exercises \\
\hline
\end{tabular}




\section{Results}

The keyword search identified 655 articles, including 128 articles in EBSCOhost, 187 articles in Cochrane, 160 articles in PubMed, 98 articles in Scopus, and 82 articles in Ovid. After removing duplicates, 404 articles were checked for relevance based on the title and abstract using the following criteria: (1) the study sample included older adults with MCI; (2) a balance intervention was conducted; (3) the study design was RCT; (4) the outcomes included objective balance measures; (5) the article reported intervention results; (6) the article was written in English. The full texts of all articles that were deemed potentially relevant were then read by the authors using the same criteria. Additional articles were identified from references in relevant review articles that were found. The current review yielded a final sample of 21 RCTs.

\subsection{Overview of Study Characteristics}

\subsubsection{Year of Publication}

The inception of balance rehabilitation studies in MCI was in the beginning of the last decade (Table 1). There has been an increase in published studies since 2011, with most studies published in $2016(n=5)[44,49-51,57]$ and $2019(n=4)[41,43,54,55]$.

\subsubsection{Sample Characteristics}

There were a total of 16 original RCTs [39-44,46,47,49,50,53,54,56-59]; five studies [45,48,51,52,55] were secondary reports of the 16 RCTs (Table 1). Therefore, in the following sections, the study percentages demonstrating study outcomes and results (Sections 3.1.7 and 3.2) were taken out of the 21 studies, while the study percentages describing other study characteristics (Sections 3.1.3-3.1.6 and 3.1.8) were taken out of the 16 original RCTs. A total of 987 older adults with MCI (age $\geq 60$ ) were analyzed in those RCTs, with a mean sample size of 62 (range: 14 to 261) per trial. Nineteen percent $(n=3)[47,49,58]$ of the original RCTs recruited only older adults with aMCI, while the remaining $81 \%(n=13)$ did not exclude older adults who had nMCI. In three original RCTs [39,43,44], cognitively intact older adults, individuals with Alzheimer's disease, and individuals with Parkinson's disease were additionally included as comparison groups.

\subsubsection{Diagnosis}

Forty-four percent $(n=7)$ [39-41,46,57-59] of the original RCTs used the Montreal Cognitive Assessment (MoCA) or a modified version of the MoCA as the primary criterion for MCI. Thirteen percent $(n=2)[44,53]$ used a score of 0.5 on the Clinical Dementia Rating (CDR) scale. Nineteen percent $(n=3)[42,49,56]$ established diagnosis through a clinical interview with a neuropsychologist or a neurologist-psychiatrist. Six percent $(n=1)$ [50] used criteria defined in the ICD-9-CM 331.83. Six percent $(n=1)$ [54] used the Addenbrooke's Cognitive Examination (ACE) score. Six percent $(n=1)$ [47] used education-adjusted scores on the Wechsler Memory Scale-Revised (WMS-R) Logical Memory II. Six percent $(n=1)$ [43] used criteria defined in the Diagnostic and Statistical Manual of Mental Disorders (DSM-IV) (Table 1).

\subsubsection{Group Design}

Most original RCTs $(44 \%, \mathrm{n}=7$ ) had a two-arm design comparing the physical training paradigm of interest with an alternative physical training paradigm $(n=2)[40,53]$ or a no-intervention control group $(n=5)[43,47,54,57,58]$ (Table 1$)$. Thirty-one percent $(n=5)$ had a two-arm design comparing a combined physical and cognitive training group with a physical training group $(\mathrm{n}=3)[41,44,50]$, a cognitive training group $(n=1)$ [49], or a no-intervention control group $(n=1)$ [46]. Thirteen percent $(n=2)[42,56]$ had a four-arm design, which included a combined physical and cognitive training group, a physical training group, a cognitive training group, and a no-intervention control or waitlist 
control group. Six percent $(n=1)$ [39] had a three-arm design, which included two combined physical and cognitive training groups with different levels of cognitive demand and a cognitive training only group. Six percent $(n=1)$ [59] had a three-arm design comparing the physical training paradigm of interest with two alternative physical training paradigms.

\subsubsection{Intervention Paradigms}

A range of intervention paradigms and combinations of paradigms were used within the included RCTs (Table 1). The most common intervention paradigms used were combined physical and cognitive intervention $(50 \%, \mathrm{n}=8)[39,41,42,44,46,49,50,56]$, followed by multimodal physical exercise $(25 \%, \mathrm{n}=4)[43,47,54,56]$, Tai Chi $(13 \%, \mathrm{n}=2)[53,58]$, ground kayak paddling exercise $(6 \%, \mathrm{n}=1)$ [40], dumbbell exercise $(6 \%, \mathrm{n}=1)$ [57], and elastic-band based exercise $(6 \%, \mathrm{n}=1)$ [59].

\subsubsection{Intervention Dosage, Intensity, and Retention}

Thirty-eight percent $(n=6)[40,41,44,46,49,50]$ of the original RCTs reported 6 to 10 weeks, $38 \%$ $(n=6)[42,43,56-59]$ reported 12 to 15 weeks, and the remaining $25 \%(n=4)[39,47,53,54]$ reported 6 to 12 months of intervention (Table 2). All the RCTs included more than 12 sessions. Most RCTs included two training sessions per week $(63 \%, n=10)[40-43,46,47,49,50,54,59], 25 \%(n=4)[44,53,57,58]$ included three sessions per week, $6 \%(\mathrm{n}=1)$ [56] included one to three sessions a week, and the remaining $6 \%(\mathrm{n}=1)$ [39] included two to five sessions a week (Table 2). Sixty-three percent $(\mathrm{n}=10)[40-43,47,49,54,56,57,59]$ had training session durations from 60 to $90 \mathrm{~min}$, and the remaining $38 \%(\mathrm{n}=6)[39,44,46,50,53,58]$ had session lengths fewer than $60 \mathrm{~min}$ (Table 2). Nineteen percent $(n=3)[44,55,59]$ designed a progressive increase in intensity during training (Table 2). Twenty-five percent $(n=4)$ included a follow-up session after the intervention program to assess for retention effects; among the four studies, three $[42,44,56]$ designed a 6-month retest interval, while the remaining study [49] had a retest three months after the intervention (Table 2). 
Table 2. Training dosage, intensity, retention, balance outcomes, and balance related findings in the RCTs included. Abbreviations: MCI mild cognitive impairment; ES effect size (Hedge's g); GUG get-up and go; TUG timed up and go; FRT functional reach test; BBS berg balance scale; OLS one-leg stance; FSST four square step test; 8UG 8-foot up and go test; ST_8UG single task in 8UG; CoV_8UG coefficient of variation of ST_8UG; DT_8UG dual task in 8UG; FRA falls rate to activity; SPPB short physical performance battery; HR harmonic ratio; FES-I fall efficacy scale-international; BESTest balance evaluation systems test; PPA physiological profile assessment; ABC activities-specific balance confidence.

\begin{tabular}{|c|c|c|c|c|c|c|c|c|}
\hline Author, Year & Training Duration & $\begin{array}{l}\text { Training Intensity } \\
\text { Progression }\end{array}$ & $\begin{array}{l}\text { Training } \\
\text { Frequency }\end{array}$ & $\begin{array}{l}\text { No. of } \\
\text { Sessions }\end{array}$ & $\begin{array}{c}\text { Length of } \\
\text { Intervention } \\
\text { Program }\end{array}$ & Retention Interval & Balance Outcomes & Balance Related Findings \\
\hline $\begin{array}{l}\text { Anderson-Hanley et al., } \\
2018 \text { [39] }\end{array}$ & $20-45 \min$ & $\mathrm{n} / \mathrm{a}$ & $2-5 \times /$ week & $\mathrm{n} / \mathrm{a}$ & 6 months & $\mathrm{n} / \mathrm{a}$ & GUG & $\begin{array}{l}\text { Performance in GUG increased significantly more in } \\
\text { exe-tour compared with exer-score group ( } \mathrm{ES}=0.31 \text { ). }\end{array}$ \\
\hline Choi and Lee, 2018 [40] & $60 \mathrm{~min}$ & $\mathrm{n} / \mathrm{a}$ & $2 \times /$ week & 12 & 6 weeks & $\mathrm{n} / \mathrm{a}$ & TUG test, FRT, and BBS & $\begin{array}{l}\text { All balance outcomes were improved in both groups. } \\
\text { The ground kayak paddling exercise was more } \\
\text { effective for improving FRT than the } \\
\text { control (ES = 1.08). }\end{array}$ \\
\hline Choi and Lee, 2019 [41] & $60 \mathrm{~min}$ & $\mathrm{n} / \mathrm{a}$ & $2 \times /$ week & 12 & 6 weeks & $\mathrm{n} / \mathrm{a}$ & $\begin{array}{l}\text { ML/AP postural sway and velocity } \\
\text { moment with eyes open/closed } \\
\text { (EO/EC), OS, TUG, FRT, BBS, } \\
\text { and FSST }\end{array}$ & 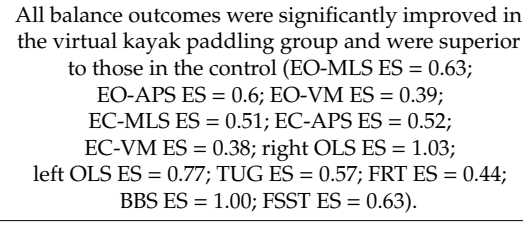 \\
\hline Donnezan et al., 2018 [42] & $60 \mathrm{~min}$ & $\mathrm{n} / \mathrm{a}$ & $2 \times /$ week & 24 & 12 weeks & $\begin{array}{l}\text { only training groups } \\
\text { evaluated at } \\
6 \text {-month retest }\end{array}$ & TUG & $\begin{array}{l}\text { TUG improved after physical training ( } \mathrm{ES}=0.50 \\
\text { vs. control) and simultaneous cognitive and physical } \\
\text { training (ES }=1.29 \text { vs. control). Retention observed at } \\
6 \text { months in the combined training group. }\end{array}$ \\
\hline $\begin{array}{l}\text { de Oliveira Silva et al., } \\
\qquad 2019 \text { [43] }\end{array}$ & $60 \mathrm{~min}$ & $\mathrm{n} / \mathrm{a}$ & $2 \times /$ week & 24 & 12 weeks & $\mathrm{n} / \mathrm{a}$ & $\begin{array}{l}\text { ST_8UG, CoV_8UG, } \\
\text { DT_8UG, DTC_8UG }\end{array}$ & $\begin{array}{c}\text { The exercise program improved ST_8UG more than } \\
\text { the control in MCI }(\mathrm{ES}=0.61) \text {. No differences } \\
\text { between training groups in individuals with } \\
\text { Alzheimer's disease. }\end{array}$ \\
\hline Mirelman et al., 2016 [44] & $45 \mathrm{~min}$ & $\begin{array}{c}\text { motor and } \\
\text { cognitive challenges } \\
\text { increased based } \\
\text { on subjects' } \\
\text { performance } \\
\end{array}$ & $3 \times /$ week & 18 & 6 weeks & 6 months & $\begin{array}{l}\text { fall rates and fall status (whether a } \\
\text { subject had } \geq 2 \text { falls), SPPB }\end{array}$ & $\begin{array}{l}\text { Fall rates and fall status improved similarly in } \\
\text { treadmill training and treadmill training plus virtual } \\
\text { reality groups in MCI. }\end{array}$ \\
\hline Del Din et al., 2020 [45] & $40 \mathrm{~min}$ & $\mathrm{n} / \mathrm{a}$ & $3 \times /$ week & 18 & 6 weeks & 6 months & number of falls, FRA & $\begin{array}{l}\text { Both treadmill training and treadmill training plus } \\
\text { virtual reality groups reduced FRA in MCI at } \\
6 \text { months post-intervention without } \\
\text { between-group interaction. }\end{array}$ \\
\hline Delbroek et al., 2017 [46] & $\begin{array}{l}\text { gradually increased } \\
\text { from } 18 \mathrm{~min} \text { in } \\
\text { week } 1 \text { to } 30 \mathrm{~min} \\
\text { in week } 5\end{array}$ & $\mathrm{n} / \mathrm{a}$ & $2 \times /$ week & 12 & 6 weeks & $\mathrm{n} / \mathrm{a}$ & iTUG, iTUG+DT, Tinetti-POMA & $\begin{array}{c}\text { The intervention group improved significantly on } \\
\text { iTUG total duration (ES }=0.05 \text { ), turn-to-sit duration } \\
\text { (ES }=0.19 \text { ), and step-time before turn (ES }=1.15 \text { ). } \\
\text { No changes over time for either group in iTUG+DT } \\
\text { or Tinetti-POMA. }\end{array}$ \\
\hline Makizako et al., 2012 [47] & $90 \mathrm{~min}$ & $\mathrm{n} / \mathrm{a}$ & $2 \times /$ week & $\mathrm{n} / \mathrm{a}$ & 6 months & $\mathrm{n} / \mathrm{a}$ & $\begin{array}{l}\text { OLS, dual task performance with } \\
\text { balance demand }\end{array}$ & $\begin{array}{l}\text { There were no significant improvement effects on } \\
\text { balance-related outcomes. }\end{array}$ \\
\hline
\end{tabular}


Table 2. Cont

\begin{tabular}{|c|c|c|c|c|c|c|c|c|}
\hline Author, Year & Training Duration & $\begin{array}{l}\text { Training Intensity } \\
\text { Progression }\end{array}$ & $\begin{array}{l}\text { Training } \\
\text { Frequency }\end{array}$ & $\begin{array}{l}\text { No. of } \\
\text { Sessions }\end{array}$ & $\begin{array}{l}\text { Length of } \\
\text { Intervention } \\
\text { Program }\end{array}$ & Retention Interval & Balance Outcomes & Balance Related Findings \\
\hline Doi et al., $2013[48]$ & $90 \mathrm{~min}$ & n/a & $2 \times /$ week & n/a & 6 months & n/a & $\mathrm{HR}$ & $\begin{array}{l}\text { The intervention group had a significant effect on the } \\
\text { vertical } \mathrm{HR}(\mathrm{ES}=0.64) .\end{array}$ \\
\hline Fogarty et al., 2016 [49] & $90 \mathrm{~min}$ & n/a & $2 \times /$ week & 20 & 10 weeks & 3 months & $\begin{array}{l}\text { postural sway on } \\
\text { regular/disturbed surfaces with } \\
\text { eyes open/closed }\end{array}$ & $\begin{array}{l}\text { No significant change in postural sway for combined } \\
\text { Taoist Tai Chi and memory intervention group } \\
\text { compared with memory intervention only group. }\end{array}$ \\
\hline $\begin{array}{l}\text { Hagovska and } \\
\text { Olekszyova, 2016 [50] }\end{array}$ & $30 \mathrm{~min}$ & $\mathrm{n} / \mathrm{a}$ & $2 \times /$ week & 20 & 10 weeks & $\mathrm{n} / \mathrm{a}$ & $\begin{array}{l}\text { FES-I, Tinetti-POMA, and } \\
\text { functional stretching, TUG }\end{array}$ & $\begin{array}{l}\text { The experimental group showed better performance } \\
\text { after training in Tinetti-POMA (ES }=0.89 \text { ) and TUG } \\
\text { ( } \mathrm{ES}=0.87 \text { ) with dual tasking. }\end{array}$ \\
\hline Hagovska et al., 2016 [51] & $30 \mathrm{~min}$ & n/a & $2 \times /$ week & 20 & 10 weeks & n/a & BESTest & $\begin{array}{l}\text { The experimental group showed better performance } \\
\text { after training in BESTest postural reaction (ES }=0.25 \text { ) } \\
\text { and total score (ES }=0.88 ; \text { largely accounted for by } \\
\text { pre-intervention rather than post-intervention } \\
\text { differences between groups). } 5 \text { other statistically } \\
\text { insignificant subscores. }\end{array}$ \\
\hline Lam et al., 2011 [52] & $30 \min$ & n/a & $3 \times /$ week & n/a & 1 year & n/a & BBS & $\begin{array}{l}\text { The intervention group showed improved BBS score } \\
2 \text { months after completing induction (the induction } \\
\text { phase lasted } 8-12 \text { weeks; ES }=0.13 \text { ). }\end{array}$ \\
\hline Lam et al., 2012 [53] & $30 \mathrm{~min}$ & n/a & $3 \times /$ week & n/a & 1 year & n/a & BBS & $\begin{array}{l}\text { The intervention group had better performance over } \\
\text { the control group at } 1 \text { year }(\mathrm{ES}=0.28) \text {. }\end{array}$ \\
\hline Langoni et al., 2019 [54] & $60 \mathrm{~min}$ & n/a & $2 \times /$ week & 48 & 6 months & n/a & BBS, TUG & $\begin{array}{l}\text { The training group showed improvement in BBS } \\
(\mathrm{ES}=1.08) \text { and TUG }(\mathrm{ES}=0.91) \text { after intervention. }\end{array}$ \\
\hline Langoni et al., 2019 [55] & $60 \mathrm{~min}$ & $\begin{array}{l}\text { increased in } \\
\text { strength exercise } \\
\text { on incremental } \\
\text { number of sets } \\
\text { and repetitions } \\
\text { and subjects' } \\
\text { performance } \\
\end{array}$ & $2 \times /$ week & 48 & 6 months & $\mathrm{n} / \mathrm{a}$ & FRT & $\begin{array}{l}\text { The training group showed improvement in FRT after } \\
\text { intervention (ES }=0.74 \text {; control group declined while } \\
\text { training group improved). }\end{array}$ \\
\hline $\begin{array}{l}\text { Lipardo and Tsang, } \\
2020[56]\end{array}$ & $60-90 \mathrm{~min}$ & $\mathrm{n} / \mathrm{a}$ & $1-3 \times /$ week & $n / a$ & 12 weeks & 6 months & fall rate, PPA, TUG & $\begin{array}{l}\text { No significant difference among groups on fall rate } \\
\text { and PPA score post intervention. TUG improved in } \\
\text { cognitive training group (ES }=0.21 \text { vs. waitlist) and } \\
\text { combined physical and cognitive training group } \\
\text { (ES }=0.55 \text { vs. waitlist; } \mathrm{ES}=0.4 \text { vs. physical only; } \\
\mathrm{ES}=0.38 \text { vs. cognitive only (primarily accounted for } \\
\text { by pre-intervention difference between groups)). }\end{array}$ \\
\hline Lü et al., $2016[57]$ & $60 \min$ & n/a & $3 \times /$ week & 36 & 12 weeks & n/a & TUG, FRT, ABC & $\begin{array}{l}\text { The intervention improved TUG performance } \\
\text { compared with control }(\mathrm{ES}=0.25) \text {. }\end{array}$ \\
\hline Sungkarat et al., 2017 [58] & $50 \mathrm{~min}$ & n/a & $3 \times /$ week & $\mathrm{n} / \mathrm{a}$ & 15 weeks & n/a & $\begin{array}{l}\text { PPA, PPA parameter scores } \\
\text { (e.g., postural away) }\end{array}$ & $\begin{array}{l}\text { Tai Chi group significantly improved PPA score } \\
(\mathrm{ES}=0.56) \text { and PPA parameter scores (e.g., postural } \\
\text { sway, ES }=0.59 \text { ) post-intervention than control. }\end{array}$ \\
\hline Yoon et al., 2017 [59] & $60 \mathrm{~min}$ & $\begin{array}{l}\text { progressively } \\
\text { increased with time }\end{array}$ & $2 \times /$ week & 24 & 12 weeks & n/a & SPPB, TUG & $\begin{array}{l}\text { SPPB increased significantly in high-speed power } \\
\text { training (HSPT) and low-speed strength training } \\
\text { (LSST) groups compared with control (ES = 0.89 for } \\
\text { HSPT, ES = 0.70 for LSST). HSPT resulted in higher } \\
\text { changes in SPPB and TUG versus LSST (ES = } 0.36 \text { for } \\
\text { SPPB, ES = } 0.35 \text { for TUG). }\end{array}$ \\
\hline
\end{tabular}




\subsubsection{Balance Outcomes}

Fifty-two percent $(n=11)$ of the 21 studies (including both the original RCTs and the secondary reports) used Get-Up and Go (GUG, $\mathrm{n}=1$ ) [39] or a modified version Timed Up-and-Go (TUG, $\mathrm{n}=9)[40-42,46,50,54,56,57,59]$ or 8-Foot $\mathrm{Up}$ and Go $(8 \mathrm{UG}, \mathrm{n}=1)[43]$ test to measure dynamic balance and agility, which required subjects to stand up from a chair, walk a defined distance and back to the chair, and sit down again. Thirty-eight percent $(\mathrm{n}=8)$ of the studies used functional reach test $(F R T)(n=4)[40,41,55,57]$, postural sway $(n=2)$ [41,49], one-leg stance (OLS, $n=2)[41,47]$, or functional stretching $(n=1)$ [50] to measure static or dynamic balance during standing under single task. Twenty-nine percent $(n=6)$ of the studies used the Berg Balance Scale $(B B S, n=5)[40,41,52-54]$ or the Balance Evaluation Systems Test (BESTest, $\mathrm{n}=1$ ) [51] to measure static and dynamic balance under multiple balance tasks. Nineteen percent $(n=4)$ used the Short Physical Performance Battery (SPPB, $\mathrm{n}=2$ ) $[44,59]$ or the Tinetti Performance Oriented Mobility Assessment (Tinetti-POMA, $n=2$ ) $[46,50]$ to assess both mobility and balance under multiple physical tasks. Fourteen percent $(n=3)$ analyzed the number of falls $(n=3)[44,45,56]$ and/or calculated the Fall Rates to Activity (FRA) Index $(n=1)$ [45]; the FRA Index takes into account both changes in number of falls and daily walking activity. Ten percent $(n=2)[56,58]$ used the Physiological Profile Assessment to measure overall risk of falls through five sensorimotor subtests. Ten percent $(n=2)$ used the Fall Efficacy Scale-I (FES-I, $n=1)$ [50] or the Activities-Specific Balance Confidence $(A B C)$ Scale $(n=1)$ [57] to measure the fear of falling. One study [41] used the Four Square Step Test (FSST) to assess the ability of subjects to step over low objects. One study [48] used harmonic ratio (HR) to measure the smoothness of trunk movement during walking.

\subsubsection{Risk of Bias}

Six percent ( $n=1$ ) [53] of the original RCTs had a double-blind design, with the trainers and assessors blinded to the treatment allocation; participants were unblinded. Sixty-three percent ( $n=10)[40,41,43,44,46,47,54,56-58]$ used a single-blind design, of which, all but one RCT blinded the outcome assessors from treatment allocation (the other RCT [54] blinded the statistician). Thirty-one percent $(n=5)[39,42,49,50,59]$ did not specify whether they masked the treatment allocation in intervention delivery or data analysis. All but one study reported no significant differences in baseline characteristics between the experimental and control groups, or accounted for baseline differences in their primary analyses. The remaining study [59] did not compare baseline characteristics in the manuscript (Table 1).

Twenty-five percent $(n=4)[39,43,53,59]$ of the original RCTs noted significant dropout rates $(>20 \%)$ and differential dropout patterns among the treatment arms (one of the studies [39] changed their randomization scheme and had subjects self-select into the treatment arm with an especially high dropout rate). Although dropout rate was less than $20 \%$, one study [49] reported that those who dropped out had significantly lower cognitive scores than those who stayed in the study (Table 1).

\subsection{Study Results}

Eighty-one percent $(n=17)[39-43,46,48,50-59]$ of the 21 studies reported beneficial effects of the targeted interventions on one or more balance outcomes, while $19 \%(n=4)[44,45,47,49]$ reported no difference between the intervention and control groups in balance outcomes (Table 2). Negative effects of rehabilitation paradigms on balance function were not reported in any studies.

Of the 17 studies that reported significant intervention effects, four studies yielded small effect sizes (Hedge's $g \approx 0.2$ ) $[39,52,53,57]$, three studies yielded medium effect sizes (Hedge's $g \approx 0.5)[43,48,58]$, and four studies yielded large effect sizes (Hedge's $g \approx 0.8$ or larger) $[40,50,54,55]$. The remaining six studies $[41,42,46,51,56,59]$ had variable effects sizes depending on the balance outcome and/or treatment group. Three studies $[41,46,51]$ had a range of small to large effect sizes among their balance outcomes (in one study [51], the large treatment effects were primarily driven by pre-intervention 
differences rather than post-intervention differences between groups). One study found a medium effect in the physical training only group and a large effect in the combined physical and cognitive training group [42]. Another study found a small effect in the cognitive training only group and a medium effect in the combined physical and cognitive training group [56]. The last study yielded large effect sizes when the two intervention groups were compared against the control group, but the difference between the two intervention groups was small [59].

Only six studies $[40,41,46,48,56,58]$ had at least the assessors blinded (single-blind), without significant dropout rates, and yielded a medium or large effect size on at least one balance measure. Choi and Lee (2018) [40] compared a ground kayak paddling exercise intervention (paddling while sitting on a chair following directions of trainers) with a home exercise control group. They found a large treatment effect in the ground kayaking group on the FRT relative to control. However, there were no significant group differences in other balance measures (TUG and BBS). The same research team followed up with a similar RCT, in which the intervention group performed kayak paddling exercises in a virtual environment (following movements of a pre-recorded kayak on a screen) [41]. In this study, statistically significant effects were found across all balance measures relative to control, and effect sizes ranged between small and large (with most in the medium range).

Delbroek et al. [46] reported that virtual reality physical and cognitive dual-task training on the BioRescue posturography platform significantly improved TUG performance, in comparison to a no-training control group. Three out of five subscores for TUG showed statistically significant effects (two with small or negligible effect sizes and one with a large effect size); five other reported measures were not statistically significant (Tinetti, four subscores for dual-task version of TUG). Another RCT compared a combined physical and cognitive training with physical training only, cognitive training only, and waitlist control [56]. No significant difference was found among groups in fall rate and PPA fall risk index post intervention, although TUG was improved in the combined training (medium effect compared to waitlist) and cognitive training only (small effect compared to waitlist) groups at follow-up. Although the study did not directly compare among the non-waitlist groups, our calculation of the effect sizes found small to medium effect (Hedges $\approx 0.4$ ) sizes when comparing the combined training group to physical training only and cognitive training only groups. Of note, the effect seen in the combined versus cognitive groups was primarily driven by a pre-intervention difference between groups rather than post-intervention difference.

Doi et al. found a medium treatment effect on the smoothness of trunk movement using a multicomponent intervention program consisting of aerobic, strength, balance, and endurance exercises, compared to an educational control group among older adults with aMCI [48]. However, there were no statistically significant difference between the intervention and control groups on the OLS and a dual task with balance demand, which the authors attributed to the balance exercise being a small part of this multicomponent intervention program [47]. Finally, Sungkarat et al. found that Tai Chi significantly improved PPA fall risk index and postural sway relative to an educational control, with medium effect sizes, among older adults with aMCI [58].

\section{Discussion}

The aim of this mapping review was to evaluate the efficacy of balance rehabilitation research conducted in older adults with MCI on their balance function, in order to inform future research and clinical care. Twenty-one studies reporting on 16 original RCTs met the inclusion criteria and were analyzed. Four studies [47-49,58] included only older adults with aMCI, while the rest included mixed $\mathrm{MCI}$ subtypes. Studies varied in their determination of MCI diagnosis, but all used acceptable criteria, such as clinician diagnoses or validated cutoff scores on established neuropsychological measures. Although the majority of the studies reported beneficial effects on one or more balance measures, many studies suffered from a myriad of methodological limitations (e.g., inadequate masking of treatment allocation, significant dropout rates) that increased their risk of bias. Two-thirds of the RCTs had a single-blind design, with the outcome assessors blinded to treatment allocation. The only 
double-blind RCT blinded the trainers and assessors but not the participants; this trial also had significant dropouts which limited its validity $[52,53]$. The remaining RCTs did not specify any masking of treatment allocation, which made them highly biased. The gold standard for RCTs is to have a triple-blind design, where trainers, assessors, and participants are blinded to treatment allocation [36]. Understandably, this may be difficult to achieve in physical training interventions as opposed to a pharmaceutical trial. However, researchers should still use an active control group (instead of no treatment) and conceal study hypotheses from the participants and study personnel to minimize placebo effects and other sources of bias.

Moreover, many studies yielded small or variable effect sizes, potentially minimizing their clinical utility. Only six studies demonstrated adequate quality evidence, with at least a single (assessor)-blind design, no significant dropouts $(>20 \%)$, and reported a medium or large effect size on at least one balance outcome measure $[40,41,46,48,56,58]$. Among these six studies, only two studies showed consistently high treatment effects above and beyond an active control group; one used a virtual kayaking intervention [41] and the other used Tai Chi [58]. That being said, neither of these studies masked the treatment allocation from the participants or the trainers, therefore increasing their degrees of bias.

Importantly, many studies did not report effect sizes, which limited the clinical interpretability of their results. In studies that did report effect sizes, most of them only calculated the post-treatment effect for each treatment arm separately, which did not elucidate whether the intervention of interest yielded a clinically relevant effect relative to control groups. The current review calculated effect sizes comparing the intervention and control groups, which often showed vastly different effect sizes from what the original trial papers reported. Taken together, more work is needed to establish an efficacious balance intervention for older adults with MCI. Future studies need to report the magnitude of treatment effects relative to control groups.

A major limitation of the literature base is the omission of falls in study outcomes. Only three studies (two original RCTs [44,56] and one secondary report [45]) measured the incidence of falls. None of these studies found a significant treatment effect in reducing falls relative to control in older adults with MCI. Thus, the currently limited literature has not demonstrated that balance interventions can reduce the fall incidence in older adults with MCI. Given the elevated risks of falls and fall-related injuries among older adults with $\mathrm{MCI}[5,6,8,9]$, more high-quality RCTs focusing on improving balance and reducing falls in this population is strongly needed. To accomplish this, prospective monitoring of falls after the intervention is recommended. However, because the number of falls need to be tracked prospectively and that may not always be easy to accomplish, examining the treatment effect on lowering the risk of falls in future studies may be a good alternative as long as the estimate of "risk of falls" is objective and accurate.

As mobility and cognition are inter-related based on common neural pathways [12], combining physical and cognitive training is a promising approach in balance rehabilitation for older adults with MCI. Only two studies utilizing a combined approach demonstrated adequate quality evidence $[46,56]$. Both studies showed highly variable effects on the balance outcomes included, each with multiple outcomes showing no statistically significant treatment effects. The probability for obtaining a type I error increases as the number of outcomes (thus number of tests) increases. In fact, in order to obtain the highest level of evidence (Class I) according to the AAN criteria for therapeutic trials, a RCT cannot have more than two primary outcome measures [36]. This prevents studies from examining a large number of outcome measures without a priori hypotheses on gold standard measures for the constructs of interest. Nevertheless, in the limited pool of adequate quality studies, it appears that combined physical and cognitive interventions may be more efficacious than physical or cognitive training alone. These will need to be confirmed with higher quality RCTs comparing a combined intervention with physical only and cognitive only control groups to elucidate the marginal efficacy of the combined intervention. Moreover, some of the studies we examined focused on cognition rather than balance as the primary construct of interest. Therefore, the researchers may not have designed the studies in order 
to maximize treatment effects on balance functions. Taken together, given the limited good quality RCTs in this area, future RCTs should target balance as the construct of interest with just one or two gold standard measures as primary outcomes, in order to detect true treatment effects.

In terms of training intensity, future studies may consider designing the interventions with increasing motor and cognitive demands, as older adults with MCI may not be able to tolerate high cognitive demands at the beginning of training. Retention effects should be examined after the interventions, as most studies did not conduct any long-term follow-ups. Possible mechanisms linking rehabilitation intervention to enhanced balance function were not demonstrated in the literature. Future studies may examine neuroimaging and/or electrophysiological outcomes before and after interventions to investigate possible neural mechanisms underlying the intervention-induced balance improvements.

\section{Conclusions}

The current mapping review identified 17 studies which showed significant treatment effects on improving balance function relative to control groups among older adults with MCI. However, only six studies demonstrated adequate quality (at least single-blind, no significant dropouts, and intervention and control groups are equivalent at baseline) and evidence (medium or large effect size on at least one balance outcome) in improving balance in this population, and none of them were double- or triple-blind. Therefore, more high-quality RCTs are needed to establish an efficacious balance intervention for older adults with MCI. Moreover, few studies examined training effects on the incidence of falls, which limits clinical utility. Future RCTs should prospectively monitor falls or changes in risk of falls after the intervention.

Author Contributions: Draft preparation, X.L. and M.H.C.; oversight and editing, G.H.Y. All authors have read and agreed to the published version of the manuscript.

Funding: This research received no external funding.

Conflicts of Interest: The authors declare no conflict of interest.

\section{References}

1. Bergen, G. Falls and fall injuries among adults aged $\geq 65$ years-United States, 2014. Morb. Mortal. Wkly. Rep. 2016, 65, 993-998. [CrossRef]

2. Burns, E.; Kakara, R. Deaths from falls among persons aged $\geq 65$ years-United States, 2007-2016. Morb. Mortal. Wkly. Rep. 2018, 67, 509. [CrossRef]

3. Florence, C.S.; Bergen, G.; Atherly, A.; Burns, E.; Stevens, J.; Drake, C. Medical costs of fatal and nonfatal falls in older adults. J. Am. Geriatr. Soc. 2018, 66, 693-698. [CrossRef]

4. Lach, H.W.; Harrison, B.E.; Phongphanngam, S. Falls and fall prevention in older adults with early-stage dementia: An integrative review. Res. Gerontol. Nurs. 2016, 10, 139-148. [CrossRef] [PubMed]

5. Ansai, J.H.; de Andrade, L.P.; Masse, F.A.A.; Gonçalves, J.; de Medeiros Takahashi, A.C.; Vale, F.A.C.; Rebelatto, J.R. Risk factors for falls in older adults with mild cognitive impairment and mild Alzheimer disease. J. Geriatr. Phys. Ther. 2019, 42, E116-E121. [CrossRef] [PubMed]

6. Tinetti, M.E.; Speechley, M.; Ginter, S.F. Risk factors for falls among elderly persons living in the community. N. Engl. J. Med. 1988, 319, 1701-1707. [CrossRef] [PubMed]

7. Van Dijk, P.T.; Meulenberg, O.G.; van de Sande, H.J.; Habbema, J.D. Falls in dementia patients. Gerontologist 1993, 33, 200-204. [CrossRef] [PubMed]

8. Delbaere, K.; Kochan, N.A.; Close, J.C.; Menant, J.C.; Sturnieks, D.L.; Brodaty, H.; Sachdev, P.S.; Lord, S.R. Mild cognitive impairment as a predictor of falls in community-dwelling older people. Am. J. Geriatr. Psychiatry 2012, 20, 845-853. [CrossRef] [PubMed]

9. Tyrovolas, S.; Koyanagi, A.; Lara, E.; Santini, Z.I.; Haro, J.M. Mild cognitive impairment is associated with falls among older adults: Findings from the Irish Longitudinal Study on Ageing (TILDA). Exp. Gerontol. 2016, 75, 42-47. [CrossRef] [PubMed] 
10. Portet, F.; Ousset, P.; Visser, P.; Frisoni, G.; Nobili, F.; Scheltens, P.; Vellas, B.; Touchon, J.; MCI Working Group of the European Consortium on Alzheimer's Disease. Mild cognitive impairment (MCI) in medical practice: A critical review of the concept and new diagnostic procedure. Report of the MCI Working Group of the European Consortium on Alzheimer's Disease. J. Neurol. Neurosurg. Psychiatry 2006, 77, 714-718. [CrossRef]

11. Petersen, R.C.; Lopez, O.; Armstrong, M.J.; Getchius, T.S.; Ganguli, M.; Gloss, D.; Gronseth, G.S.; Marson, D.; Pringsheim, T.; Day, G.S. Practice guideline update summary: Mild cognitive impairment: Report of the Guideline Development, Dissemination, and Implementation Subcommittee of the American Academy of Neurology. Neurology 2018, 90, 126-135. [CrossRef] [PubMed]

12. Montero-Odasso, M.; Verghese, J.; Beauchet, O.; Hausdorff, J.M. Gait and cognition: A complementary approach to understanding brain function and the risk of falling. J. Am. Geriatr. Soc. 2012, 60, 2127-2136. [CrossRef] [PubMed]

13. Mirelman, A.; Herman, T.; Brozgol, M.; Dorfman, M.; Sprecher, E.; Schweiger, A.; Giladi, N.; Hausdorff, J.M. Executive function and falls in older adults: New findings from a five-year prospective study link fall risk to cognition. PLoS ONE 2012, 7, e40297. [CrossRef] [PubMed]

14. Welmerink, D.B.; Longstreth Jr, W.; Lyles, M.F.; Fitzpatrick, A.L. Cognition and the risk of hospitalization for serious falls in the elderly: Results from the Cardiovascular Health Study. J. Gerontol. Ser. A Biomed. Sci. Med. Sci. 2010, 65, 1242-1249. [CrossRef] [PubMed]

15. Fischer, B.L.; Gleason, C.E.; Gangnon, R.E.; Janczewski, J.; Shea, T.; Mahoney, J.E. Declining cognition and falls: Role of risky performance of everyday mobility activities. Phys. Ther. 2014, 94, 355-362. [CrossRef] [PubMed]

16. Boripuntakul, S.; Lord, S.; Brodie, M.; Smith, S.T.; Methapatara, P.; Wongpakaran, N.; Sungkarat, S. Spatial variability during gait initiation while dual tasking is increased in individuals with mild cognitive impairment. J. Nutr. Health Aging 2014, 18, 307-312. [CrossRef]

17. Hunter, S.W.; Divine, A.; Frengopoulos, C.; Odasso, M.M. A framework for secondary cognitive and motor tasks in dual-task gait testing in people with mild cognitive impairment. BMC Geriatr. 2018, 18, 202. [CrossRef]

18. Kelly, V.E.; Eusterbrock, A.J.; Shumway-Cook, A. A review of dual-task walking deficits in people with Parkinson's disease: Motor and cognitive contributions, mechanisms, and clinical implications. Parkinson's Dis. 2012, 2012, 1-14. [CrossRef]

19. Montero-Odasso, M.M.; Sarquis-Adamson, Y.; Speechley, M.; Borrie, M.J.; Hachinski, V.C.; Wells, J.; Riccio, P.M.; Schapira, M.; Sejdic, E.; Camicioli, R.M. Association of dual-task gait with incident dementia in mild cognitive impairment: Results from the gait and brain study. JAMA Neurol. 2017, 74, 857-865. [CrossRef]

20. Mignardot, J.-B.; Beauchet, O.; Annweiler, C.; Cornu, C.; Deschamps, T. Postural sway, falls, and cognitive status: A cross-sectional study among older adults. J. Alzheimer's Dis. 2014, 41, 431-439. [CrossRef]

21. Hauer, K.; Pfisterer, M.; Weber, C.; Wezler, N.; Kliegel, M.; Oster, P. Cognitive impairment decreases postural control during dual tasks in geriatric patients with a history of severe falls. J. Am. Geriatr. Soc. 2003, 51, 1638-1644. [CrossRef] [PubMed]

22. Leandri, M.; Cammisuli, S.; Cammarata, S.; Baratto, L.; Campbell, J.; Simonini, M.; Tabaton, M. Balance features in Alzheimer's disease and amnestic mild cognitive impairment. J. Alzheimer's Dis. 2009, 16, 113-120. [CrossRef] [PubMed]

23. Deschamps, T.; Beauchet, O.; Annweiler, C.; Cornu, C.; Mignardot, J.-B. Postural control and cognitive decline in older adults: Position versus velocity implicit motor strategy. Gait Posture 2014, 39, 628-630. [CrossRef] [PubMed]

24. Tangen, G.G.; Engedal, K.; Bergland, A.; Moger, T.A.; Mengshoel, A.M. Relationships between balance and cognition in patients with subjective cognitive impairment, mild cognitive impairment, and Alzheimer disease. Phys. Ther. 2014, 94, 1123-1134. [CrossRef]

25. Sparto, P.J.; Rosso, A.L.; Divecha, A.A.; Metti, A.L.; Rosano, C. Shared neural substrates of cognitive function and postural control in older adults. Alzheimer's Dement. 2020, 16, 621-629. [CrossRef]

26. Shin, B.M.; Han, S.J.; Jung, J.H.; Kim, J.E.; Fregni, F. Effect of mild cognitive impairment on balance. J. Neurol. Sci. 2011, 305, 121-125. [CrossRef] 
27. Goyal, N.; Lee, Y.; Luna, G.; Aruin, A.S. Individual and combined effects of a cognitive task, light finger touch, and vision on standing balance in older adults with mild cognitive impairment. Aging Clin. Exp. Res. 2019, 32, 797-807. [CrossRef]

28. Bahureksa, L.; Najafi, B.; Saleh, A.; Sabbagh, M.; Coon, D.; Mohler, M.J.; Schwenk, M. The impact of mild cognitive impairment on gait and balance: A systematic review and meta-analysis of studies using instrumented assessment. Gerontology 2017, 63, 67-83. [CrossRef]

29. Hsu, C.L.; Best, J.R.; Chiu, B.K.; Nagamatsu, L.S.; Voss, M.W.; Handy, T.C.; Bolandzadeh, N.; Liu-Ambrose, T. Structural neural correlates of impaired mobility and subsequent decline in executive functions: A 12-month prospective study. Exp. Gerontol. 2016, 80, 27-35. [CrossRef]

30. Maidan, I.; Droby, A.; Jacob, Y.; Giladi, N.; Hausdorff, J.M.; Mirelman, A. The neural correlates of falls: Alterations in large-scale resting-state networks in elderly fallers. Gait Posture 2020, 80, 56-61. [CrossRef]

31. Hsu, C.L.; Voss, M.W.; Handy, T.C.; Davis, J.C.; Nagamatsu, L.S.; Chan, A.; Bolandzadeh, N.; Liu-Ambrose, T. Disruptions in brain networks of older fallers are associated with subsequent cognitive decline: A 12-month prospective exploratory study. PLoS ONE 2014, 9, e93673. [CrossRef] [PubMed]

32. Ogama, N.; Sakurai, T.; Shimizu, A.; Toba, K. Regional white matter lesions predict falls in patients with amnestic mild cognitive impairment and Alzheimer's disease. J. Am. Med. Dir. Assoc. 2014, 15, 36-41. [CrossRef] [PubMed]

33. Crockett, R.A.; Hsu, C.L.; Best, J.R.; Beauchet, O.; Liu-Ambrose, T. Head over heels but I forget why: Disruptive functional connectivity in older adult fallers with mild cognitive impairment. Behav. Brain Res. 2019, 376, 112104. [CrossRef] [PubMed]

34. Makizako, H.; Shimada, H.; Doi, T.; Park, H.; Yoshida, D.; Uemura, K.; Tsutsumimoto, K.; Liu-Ambrose, T.; Suzuki, T. Poor balance and lower gray matter volume predict falls in older adults with mild cognitive impairment. BMC Neurol. 2013, 13, 102. [CrossRef] [PubMed]

35. Crockett, R.A.; Hsu, C.L.; Best, J.R.; Liu-Ambrose, T. Resting state default mode network connectivity, dual task performance, gait speed, and postural sway in older adults with mild cognitive impairment. Front. Aging Neurosci. 2017, 9, 423. [CrossRef] [PubMed]

36. Gronseth, G.S.; Cox, J.; Gloss, D.; Merillat, S.; Dittman, J.; Armstrong, M.J.; Getchius, T.S.D. 2017 Edition Clinical Practice Guideline Process Manual; American Academy of Neurology: Minneapolis, MN, USA, 2017.

37. Morris, S.B. Estimating effect sizes from pretest-posttest-control group designs. Organ. Res. Methods 2008, 11, 364-386. [CrossRef]

38. Hedges, L.; Olkin, I. Statistical Methods for Meta-Analysis; Academic Press: Cambridge, MA, USA, 2014.

39. Anderson-Hanley, C.; Barcelos, N.M.; Zimmerman, E.A.; Gillen, R.W.; Dunnam, M.; Cohen, B.D.; Yerokhin, V.; Miller, K.E.; Hayes, D.J.; Arciero, P.J.; et al. The Aerobic and Cognitive Exercise Study (ACES) for Community-Dwelling Older Adults With or At-Risk for Mild Cognitive Impairment (MCI): Neuropsychological, Neurobiological and Neuroimaging Outcomes of a Randomized Clinical Trial. Front. Aging Neurosci. 2018, 10, 76. [CrossRef]

40. Choi, W.; Lee, S. Ground Kayak Paddling Exercise Improves Postural Balance, Muscle Performance, and Cognitive Function in Older Adults with Mild Cognitive Impairment: A Randomized Controlled Trial. Med. Sci. Monit. 2018, 24, 3909-3915. [CrossRef]

41. Choi, W.; Lee, S. The effects of virtual kayak paddling exercise on postural balance, muscle performance, and cognitive function in older adults with mild cognitive impairment: A randomized controlled trial. J. Aging Phys. Act. 2019, 27, 861-870. [CrossRef]

42. Combourieu Donnezan, L.; Perrot, A.; Belleville, S.; Bloch, F.; Kemoun, G. Effects of simultaneous aerobic and cognitive training on executive functions, cardiovascular fitness and functional abilities in older adults with mild cognitive impairment. Ment. Health Phys. Act. 2018, 15, 78-87. [CrossRef]

43. de Oliveira Silva, F.; Ferreira, J.V.; Placido, J.; Sant'Anna, P.; Araujo, J.; Marinho, V.; Laks, J.; Camaz Deslandes, A. Three months of multimodal training contributes to mobility and executive function in elderly individuals with mild cognitive impairment, but not in those with Alzheimer's disease: A randomized controlled trial. Maturitas 2019, 126, 28-33. [CrossRef]

44. Mirelman, A.; Rochester, L.; Maidan, I.; Del Din, S.; Alcock, L.; Nieuwhof, F.; Rikkert, M.O.; Bloem, B.R.; Pelosin, E.; Avanzino, L.; et al. Addition of a non-immersive virtual reality component to treadmill training to reduce fall risk in older adults (V-TIME): A randomised controlled trial. Lancet 2016, 388, 1170-1182. [CrossRef] 
45. Del Din, S.; Galna, B.; Lord, S.; Nieuwboer, A.; Bekkers, E.M.J.; Pelosin, E.; Avanzino, L.; Bloem, B.R.; Olde Rikkert, M.G.M.; Nieuwhof, F.; et al. Falls Risk in Relation to Activity Exposure in High-Risk Older Adults. J. Gerontol. Ser. A 2020, 75, 1198-1205. [CrossRef] [PubMed]

46. Delbroek, T.; Vermeylen, W.; Spildooren, J. The effect of cognitive-motor dual task training with the biorescue force platform on cognition, balance and dual task performance in institutionalized older adults: A randomized controlled trial. J. Phys. Ther. Sci. 2017, 29, 1137-1143. [CrossRef] [PubMed]

47. Makizako, H.; Doi, T.; Shimada, H.; Yoshida, D.; Tsutsumimoto, K.; Uemura, K.; Suzuki, T. Does a multicomponent exercise program improve dual-task performance in amnestic mild cognitive impairment? A randomized controlled trial. Aging Clin. Exp. Res. 2012, 24, 640-646. [CrossRef]

48. Doi, T.; Makizako, H.; Shimada, H.; Yoshida, D.; Tsutsumimoto, K.; Sawa, R.; Misu, S.; Suzuki, T. Effects of multicomponent exercise on spatial-temporal gait parameters among the elderly with amnestic mild cognitive impairment (aMCI): Preliminary results from a randomized controlled trial (RCT). Arch. Gerontol. Geriatr. 2013, 56, 104-108. [CrossRef]

49. Fogarty, J.N.; Murphy, K.J.; McFarlane, B.; Montero-Odasso, M.; Wells, J.; Troyer, A.K.; Trinh, D.; Gutmanis, I.; Hansen, K.T. Taoist Tai Chi ${ }^{\circledR}$ and Memory Intervention for Individuals with Mild Cognitive Impairment. J. Aging Phys. Act. 2016, 24, 169-180. [CrossRef]

50. Hagovska, M.; Olekszyova, Z. Impact of the combination of cognitive and balance training on gait, fear and risk of falling and quality of life in seniors with mild cognitive impairment. Geriatr. Gerontol. Int. 2016, 16, 1043-1050. [CrossRef]

51. Hagovska, M.; Takac, P.; Dzvonik, O. Effect of a combining cognitive and balanced training on the cognitive, postural and functional status of seniors with a mild cognitive deficit in a randomized, controlled trial. Eur. J. Phys. Rehabil. Med. 2016, 52, 101-109.

52. Lam, L.C.; Chau, R.C.; Wong, B.M.; Fung, A.W.; Lui, V.W.; Tam, C.C.; Leung, G.T.; Kwok, T.C.; Chiu, H.F.; $\mathrm{Ng}$, S.; et al. Interim follow-up of a randomized controlled trial comparing Chinese style mind body (Tai Chi) and stretching exercises on cognitive function in subjects at risk of progressive cognitive decline. Int. J. Geriatr. Psychiatry 2011, 26, 733-740. [CrossRef]

53. Lam, L.C.W.; Chau, R.C.M.; Wong, B.M.L.; Fung, A.W.T.; Tam, C.W.C.; Leung, G.T.Y.; Kwok, T.C.Y.; Leung, T.Y.S.; Ng, S.P.; Chan, W.M. A 1-Year Randomized Controlled Trial Comparing Mind Body Exercise (Tai Chi) With Stretching and Toning Exercise on Cognitive Function in Older Chinese Adults at Risk of Cognitive Decline. J. Am. Med. Dir. Assoc. 2012, 13, 568.e515-568.e520. [CrossRef] [PubMed]

54. Langoni, C.D.; Resende, T.D.; Barcellos, A.B.; Cecchele, B.; da Rosa, J.N.; Knob, M.S.; Silva, T.D.; Diogo, T.D.; da Silva, I.G.; Schwanke, C.H.A. The effect of group exercises on balance, mobility, and depressive symptoms in older adults with mild cognitive impairment: A randomized controlled trial. Clin. Rehabil. 2019, 33, 439-449. [CrossRef] [PubMed]

55. Da Langoni, C.S.; de Resende, T.L.; Barcellos, A.B.; Cecchele, B.; Knob, M.S.; do Silva, T.N.; da Rosa, J.N.; de Diogo, T.S.; da Filho, I.G.S.; Schwanke, C.H.A. Effect of Exercise on Cognition, Conditioning, Muscle Endurance, and Balance in Older Adults With Mild Cognitive Impairment: A Randomized Controlled Trial. J. Geriatr. Phys. Ther. 2019, 42, E15-E22. [CrossRef] [PubMed]

56. Lipardo, D.S.; Tsang, W.W. Effects of combined physical and cognitive training on fall prevention and risk reduction in older persons with mild cognitive impairment: A randomized controlled study. Clin. Rehabil. 2020, 34, 773-782. [CrossRef] [PubMed]

57. Lü, J.; Sun, M.; Liang, L.; Feng, Y.; Pan, X.; Liu, Y. Effects of momentum-based dumbbell training on cognitive function in older adults with mild cognitive impairment: A pilot randomized controlled trial. Clin. Interv. Aging 2016, 11, 9-16. [CrossRef] [PubMed]

58. Sungkarat, S.; Boripuntakul, S.; Chattipakorn, N.; Watcharasaksilp, K.; Lord, S.R. Effects of Tai Chi on Cognition and Fall Risk in Older Adults with Mild Cognitive Impairment: A Randomized Controlled Trial. J. Am. Geriatr. Soc. 2017, 65, 721-727. [CrossRef] [PubMed] 
59. Yoon, D.H.; Kang, D.; Kim, H.J.; Kim, J.S.; Song, H.S.; Song, W. Effect of elastic band-based high-speed power training on cognitive function, physical performance and muscle strength in older women with mild cognitive impairment. Geriatr. Gerontol. Int. 2017, 17, 765-772. [CrossRef]

Publisher's Note: MDPI stays neutral with regard to jurisdictional claims in published maps and institutional affiliations.

(C) 2020 by the authors. Licensee MDPI, Basel, Switzerland. This article is an open access article distributed under the terms and conditions of the Creative Commons Attribution (CC BY) license (http://creativecommons.org/licenses/by/4.0/). 